\title{
Twist Lock Unlocking Process Research and Unlocking Fixture Design in Container Terminals
}

\author{
Panpan Zhang ${ }^{1,2, a}$, Chen Xie ${ }^{1,2, b}$ and Haibo Fei ${ }^{1,2, c}$ \\ ${ }^{1}$ China Waterborne Transport Research Institute, Beijing 100088, China \\ ${ }^{2}$ Key Laboratory of Logistics Equipment \& Control Engineering, Beijing 100088, China \\ apeterpan9152@126.com, bch_xie@wti.ac.cn, ${ }^{\mathrm{c}}$ feihb@wti.ac.cn
}

Keywords: container, container lock, twist lock, unlocking process, automatic fast-unlocking.

\begin{abstract}
With the development of the container transportation and the urgent demand of the fast-unlocking of container handling, the securing and unlocking technologies are more and more important. Types of container securing equipment such as the locating cone and the locking base were introduced. The unlocking process of twisted locks were analyzed. Meanwhile, the bottlenecks of the existent unlocking process was summarized. With the need of the container fast-unlocking technology increasing, the automatic fast-unlocking process was summarized. And future prospects of the unlocking technology and process were mentioned.
\end{abstract}

\section{Introduction}

Containerization is an effective loading method. And in developed countries such as US, England and Japan, 70\%-90\% of goods for imports and exports was fulfilled in the container way. With the fast development of containerization, technologies for container vessels have been rapidly developing. Larger and larger container vessels are put into market. The loading ratio of container vessels are increasing. So far container stacking is up to 7 storeies with a height of over 18 meter above the deck [1]. Therefore, the securing devices are critical for the container shipping. However, the existence of such devices requires extra steps for the stevedoring process in container terminals. As the containerization goes on, high speed and automation demands for container stevedoring are urgent.

In this paper, securing devices for container transportation were introduced. And the twist lock which is a kind of securing devices is emphasized. Based on the traditional equipment in the container terminals, the twist lock unlocking processes were analyzed. The disadvantages of the existent processes were summarized. Based on the developments of automation, processes for fast-unlocking were studied. After the analysis of twist lock unlocking, a twist lock fixture for automatic fast-unlocking process was designed.

\section{Securing Devices}

Securing devices basically include locating cones, bases, baseboards, lashing devices and twist locks [2-4].

There are two different types of locating cones which are single cone and double cone. Locating cones are used for the horizontal connections. The double cones are used for two containers connections in the transverse direction. The bases are usually made to compensate the height difference between the adjacent containers. The baseboard is used for locating base locks. After the baseboard and base locks are fixed, the container can be placed on the base locks and the locks could be set to the locking condition.

Lashing devices shown in Figure 1 including straining bars, chains, D-shaped rings are basically used for the fixation on the side of containers.

When the fixations between the deck and the container or different containers are necessary, twist locks are put into application. There are mainly three different types of twist locks according to the 
working methods which are base locks, manual twist locks, semi-automatic twist locks and full automatic twist locks.

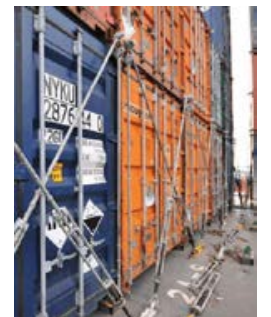

Figure.1 lashing devices for containers

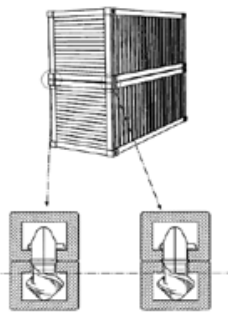

Figure.2 the twist lock for containers

Twist locks are placed in the corner fittings of different containers shown in Figure 2 and used for vertical connection. There are many kinds of twist locks for containers. At the same time, unlocking methods for twist locks are various. In this paper, only one kind of twist locks which is widely used was discussed.

Twist locks popularly applied in container terminals are focused and discussed. Taking the semi-automatic twist lock with single clasp for example, such a lock shown in Figure 3 mainly comprise one upper lock head, one lower lock head, one lock base, one clasp and one fastener. When the twist lock is used in securing containers, the upper lock head is attached in the corner fitting of an upper container and the lower lock head is attached in the corner fitting of a lower container. When the container vessel arrives at the berths of the terminal, lower lock heads are released form corner fittings of lower container so that containers can be elevated by cranes from the ship and then are put on the truck. Next step is to unlock the upper lock heads from the corner fittings of upper containers.
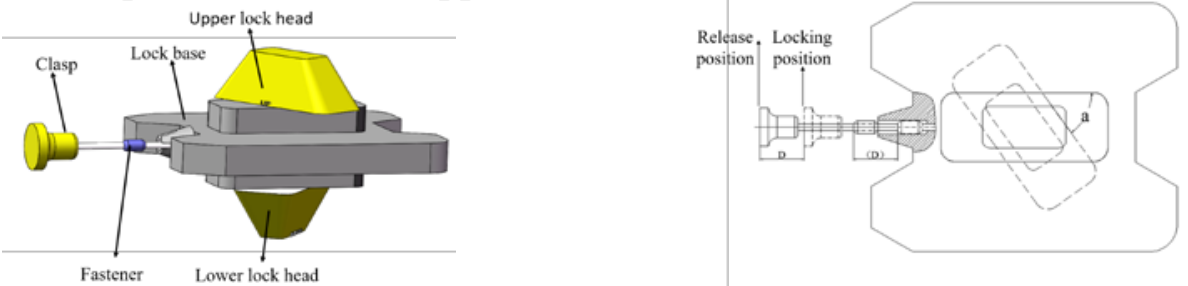

Figure.3 a typical kind of twist locks Figure.4 Schematic diagram for twist lock unlocking

In the locking condition of upper lock heads shown in Figure 4, there is an angle named as $\alpha$ between the upper lock head and the lock base. When the clasp is pulled out a certain distance $\mathrm{D}$, the lock head can rotate and parallel with the lock bases. And then the lock head can be removed from corner fittings.

\section{Manual Unlocking Process for Container Unloading}

After the ship arrives at the container terminal, stevedores firstly unlock the lower lock head with a special beam in order to unload the containers. While the upper lock head is still attached to the upper container. Quayside container cranes are applied to unload containers. However, before containers are placed on the horizontal transportation vehicles, the upper lock head of the twist lock has to be unlocked and removed from containers. For different cranes and transportation vehicles, the unlocking process for container unloading are comparatively different.

When the quayside container cranes with single trolley is chosen as the unloading equipment and the container truck is selected as the horizontal transportation vehicle, the unlocking process is shown in Figure 5. The container is lifted from the vessel and then placed on the truck; the truck is driven to a designated area where several stevedores unlocked the twist locks. After that, trucks can be driven to the storage yard or to the clients.

In container terminals, once the straddle carrier or the automatic guided vehicle (AGV) is usually chosen as the horizontal transportation equipment, the unlocking processes for them are similar to 
that of the container truck except that the twist locks are unlocked near the ground. After locks are removed, the container is placed on the ground or on the AGV shown in Figure 6 .

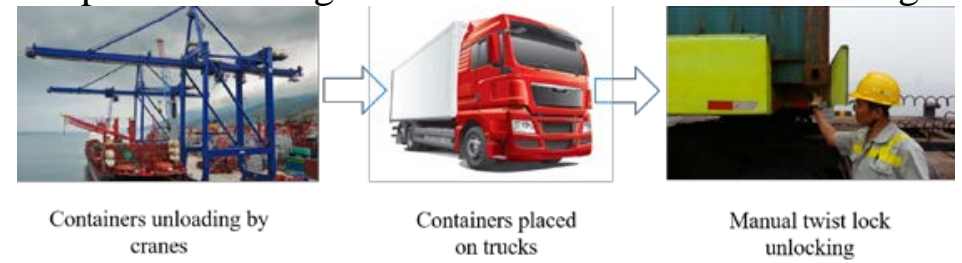

Figure.5 Container trucks used for transportation

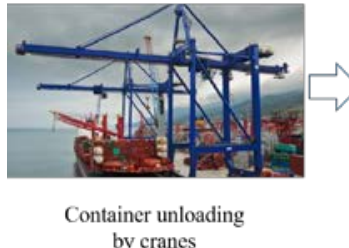

by cranes

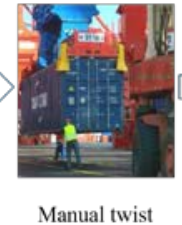

lock unlocking

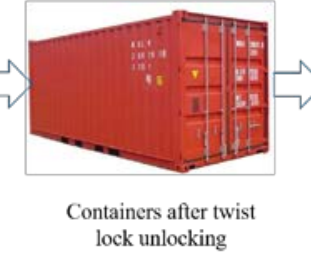

lock unlocking

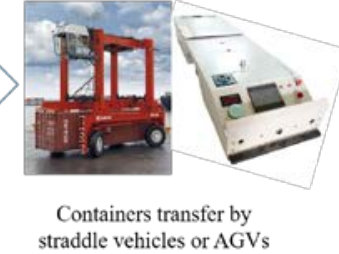

traddle vehicles or AGVs

Figure.6 Straddle carrier used for transportation

As technologies for the port machinery rapidly develop, a container cranes with double trolleys was studied and put into use shown in Figure 7. This kind of cranes was developed to solve serial problems of post-Panama container vessel such as the lifting height, suspension length and position for container trucks. The trolley with a lifting height of over 40 meter on the ocean side unloads containers from vessel and put them on the transfer platform. The trolley on the land side which is usually less than 15 meter high takes containers from the transfer platform to the ground transportation vehicles. The unlocking process for twist locks is carried out by stevedores on the transfer platform shown in Figure 8.

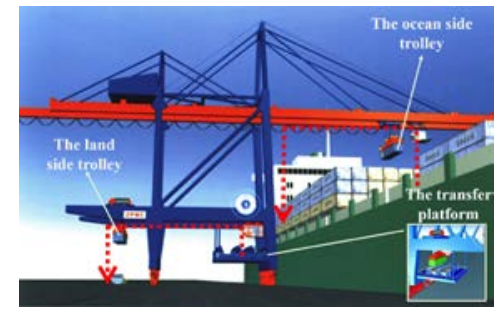

Figure.7 structure of the container crane with double trolleys

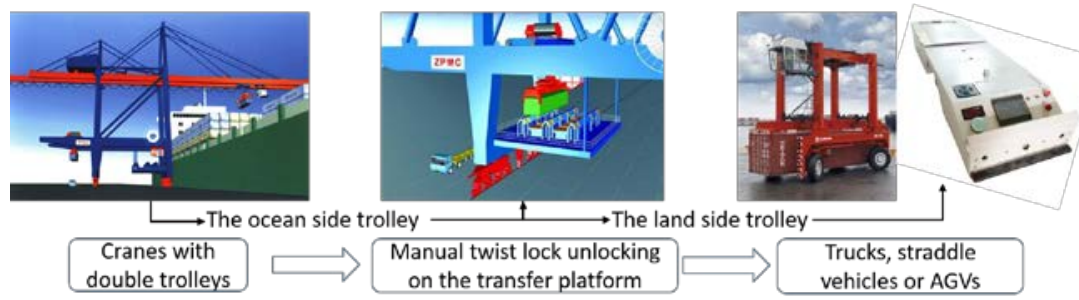

Figure.8 Manual unlocking process for a container crane with double trolleys

It should be noted that the efficiency of the container unloading must be in accordance with the twist lock unlocking process. For the crane with double trolleys, if the ocean side trolley takes two 40 -feet containers (two 45-feet containers or four 20-feet container) to the transfer platform, the land side trolley with a standard double container spreader is needed. Thus the land side trolley can carry containers from a truck or an AGV. In this way, the working efficiencies of the two trolleys can be compatible.

\section{Disadvantages of Manual Unlocking Process}

There are many types of twist locks and unlocking processes. And some companies have work on the development of new locks[5-13]. However in container terminals, manual way to unlocking twist 
locks is still the main stream. For a quayside container crane, at least two stevedores are needed for the unlocking work. And for a container vessel which is 200 meter long, lots of stevedores are usually necessary under the crane working scope to carry out the simple and repetitive procedure.

The existent twist lock unlocking process bring two main disadvatages to the container terminals. On one hand, the working environment is very dangerous and accidents happened a lot in the terminals because of the vehicles such as trucks, straddle vehicles and fork trucks on court. On the other hand, the bottlenecks of twist lock unlocking greatly affect the development of automation in container terminals.

\section{Automatic Unlocking Process for Container Unloading}

In 2015, a twist lock unlocking platform invented by Bromma was issued [18]. If the unlocking technology is applied in container terminals, the container unloading process will be different, especially for the crane with single trolley. And when the container truck is used for transportation, the unlocking process actually makes big difference. First, the container is carried from the ship and then the container is placed on an unlocking platform and the mooring cables which are used for lifting containers are loosened a bit so that the container can be totally placed on the platform due to the gravity. After twist locks are unlocked and removed, containers will be lifted again from the unlocking platform and will be put on the container truck or AGV.

For cranes with double trolleys, the automatic unlocking process is quite similar to the manual process except that stevedores are not necessary on the transfer platform.

And in the automatic twist lock unlocking process, dimension of the unlocking platform should be consistent to dimensions of containers. Generally speaking, there are four corner fitting on one container. So four fixtures are necessary for one container.

\section{Fixture Design for the Twist Lock Unlocking}

In the design, a force gauge (Brand: HANDPI. Type:HP-1K, Range:0-1000 N, Accuracy: $\pm 0.5 \%$ ) was selected to test the force applied on the clasp of the twist lock shown in Figure 9. Through the test, the force applied on the clasp is around $200 \mathrm{~N}$ when the upper lock head is removed.

The fixture shown in Figure 10 comprises a support base and a clamping jaw. The entire fixture can be integrated to a manipulator.The support base integrates the guide rail which provides guidance for twist locks. The clamping jaw is used for grabbing and loosening the clasp.The clamping jaw can be electrically, hydraulically or pneumatically driven. Based on the results of force test, the type of drive can be chosen.

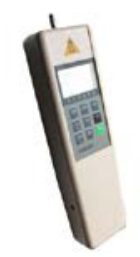

Figure.9 the force gauge

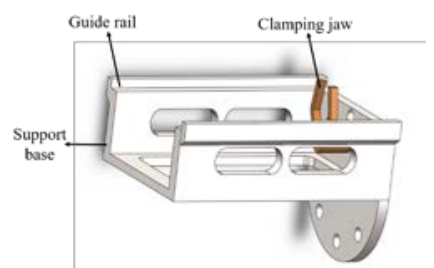

Figure 10 Schematic diagram of the fixture for twist lock

Because the positions of twist locks on containers are relatively defined, the support base is necessary for twist locks to move along the guide rail. When the clasp gets the setting position, the 
clasp is closed and the fixture is moved along the guide rail direction. When the clasp is pulled out at a distance of $\mathrm{D}$, the lock is released and fall onto the support base. And then the clamp jaw is loosened. With the help of manipulator, the fixture can be moved upon the collecting box and unload locks to the box.
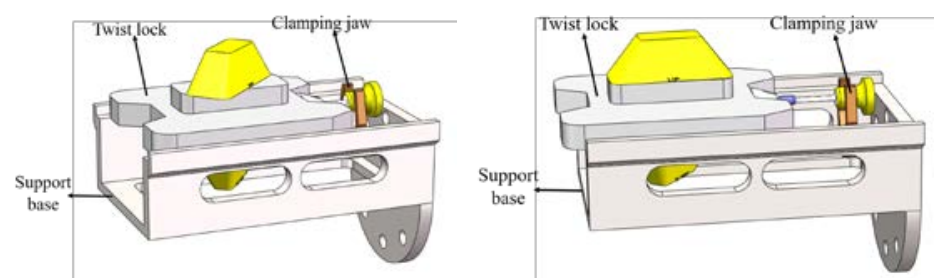

Figure11. Diagram for the fixture working process

\section{Conclusion}

In this paper, securing devices for containers were introduced. Characteristics of twist locks were emphasized. With the development of the container transportation and the urgent demand of the fast-unlocking of container handling,the manual unlocking processes were analyzed and the bottlenecks of the existent unlocking process was discussed.

Based on the automation technology, a fixture for twist lock unlocking was designed. The fixture can be combined with a manipulator to unlock the twist lock with single clasp At the same time, automatic unlocking processes for container unloading were put forward. Advice for the automatic unlocking was given. And it should be paid much attention that, the efficiencies of the crane and horizontal transportation vehicles must be compatible during the process design.

\section{References}

[1] Xu Yong, Suggestions for securing technologies of containers, Shanghai Shipbuilding. 2007, 2, p.31-33.

[2] Dong Wenhai, Wang Shengli, Wu Shengchun, Securing operations for container vessels, World Shipping. 2012, 35(6), p. 37-39.

[3] Zhang Bin, Securing devices for containers, Jiangsu Ship, 2011, 28(6), p.14-16.

[4] Xie Chen, Zhang Panpan, Fei Haibo, Status and development trend of twist locks for containers, China Water Transport ,2015, (7) , p.38-40,132.

[5] Huang Dongxue, a new kind of twist locks for containers, Marine Technical News \&Trends. 1995, 12, p.25.

[6] Information on: http://www.shippingchina.com/html/htmlnews/temp/brmaininfo5446.html.

[7] Peter Walker, methods of container securing system, China, 200980118116. 2, 2009.

[8] Raymond M. Del Acqua, Container corner post locking assembly, US, 4341495A, 1982.

[9] Clyde R. Cain, Cargo container interlock system, US, 3980185A, 1976.

[10]Peter Walker, Integrated corner casting locking mechanism for shipping containers, US, 7014234B2, 2006.

[11]Long Kaifeng, a fast fixing method and device for large box, China, 200620133622.2, 2006.

[12]Zhang Chao, a kind of securing mechanism for containers, China, 201220451935.8[P], 2012.

[13]Liu Yang, Zhang Wei, Zhuang Xinchuan, Design of automatic release device for container twist locks, Science \& Technology of Ports. 2012, 10, p.27-18.

[14]Information on: http://www.bromma.com/show.php?id=1524288 